\title{
FRAMEWORK AGREEMENT ON CLIMATE CHANGE: A SCIENTIFIC AND POLICY HISTORY
}

\author{
ALAN D. HECHT* and DENNIS TIRPAK* \\ U.S. Environmental Protection Agency, 401 M Street, SW, Washington, D.C. 20460, U.S.A.
}

\begin{abstract}
Authors Introduction. In the introduction to his new book, The Agenda, Washington Post Editor and writer, Bob Woodward, described the book as something between newspaper journalism and history. Woodward notes that "in the information cycle, the newspapers, television and magazines prove the first waves of explanation of events in the days or weeks after they occur. Then, generally after a long interlude, insiders memoirs or histories appear." The Agenda, according to Woodward, "is a hybrid combining the thoroughness of history with the contemporaneity of journalism."

This paper is also a mixture of journalism and history. It is journalistic in the sense of providing an annotated chronology of key events and publications since 1970 that ultimately led to the signing of the Framework Agreement on Climate Change (herein referred to as the 'Convention'). It is also history in that we share our insight on these events and offer our perspective of how science and policy-making interacted.

After the signing of the Climate Convention at the Earth Summit in Rio de Janeiro (June, 1992), the authors began to think about the many events that led to this historic agreement. When did the process really begin? What were the seminal scientific papers? When did climate change become a policy issue? What lessons do we learn for the future?

We began to review the history and soon recognized there was no clear beginning to either the science or policy story. Both aspects evolved, with science and policy decisions affecting each other. The resulting history is decidedly a U.S. perspective. While there will no doubt be arguments over the significance of all the events cited as well as the omission of others, we have for the first time synthesized the major themes that led to the climate convention.

Our discussion is organized into three periods of time: 1970-1980 (ending with the first World Climate Conference), 1980-1987 (ending with the U.S. presidential election), and 1988-1992 (signing of the Convention). For each period there is an overall summary and analysis followed by a chronology of selected events.
\end{abstract}

\section{Summary}

A framework agreement on climate change was signed by 154 nations in Rio de Janeiro during the United Nations Conference on Environment and Development (UNCED), June 3 to 14, 1992. The convention came into effect on March 21, 1994 when more than 50 nations ratified the agreement.

The carefully chosen but often contorted language in the convention was the end result of more than two years of intense international negotiations and debate between the U.S. and European Community (E.C.) countries on approaches and commitments toward stabilizing greenhouse gases, and between developed and

* Alan D. Hecht is the Principal Deputy Assistant Administrator of the Office of International Activities and Dennis Tirpak is the Director of the Global Change Division, Office of Policy and Planning, Environmental Protection Agency (EPA), 401 M Street, SW, Washington, DC 20460. 
developing countries on overall responsibilities and commitments, technical assistance and financial support to implement the agreement.

The Convention set as its ultimate objective achieving "stabilization of greenhouse gas concentrations in the atmosphere at a level that would prevent dangerous anthropogenic interference with the climate system." The more immediate goal was to return global greenhouse gas emissions to 1990 levels by the end of the century. Major provisions of the Convention include:

- preparing national reports on how to reduce emissions and/or expand carbon sinks,

- providing financial and technical assistance to developing countries for inventories of greenhouse gas emissions,

- continuing scientific and economic analyses with options to revise the Agreement based on new scientific information, and

- promoting peer review of developed countries national plans.

Political actions taken to address global warming rest on scientific evidence influenced largely by results of numerical climate modeling. The United States, beginning in the late 1960's led scientific efforts in numerical atmospheric modeling. The results of climate modeling experiments combined with a better understanding of the radiative properties of greenhouse gases and empirical climate data led to the conclusion that man-induced climate change was a potentially serious global risk.

The recognition of global warming as a national policy issue evolved slowly in the United States. In the late 1960's and early 1970's policy attention was focused on the causes and impacts of climatic variations. Drought in sub-Sahara Africa from 1968 to 1972 caused widespread human suffering. In 1972, as international relief efforts gathered momentum, drought also reduced grain production in the Soviet Union, China, Eastern Europe, and Latin America. Grain prices increased dramatically worldwide, which stressed food-importing countries and hampered the African relief efforts.

In 1976, record breaking cold winters in the U.S. and Europe had major economic consequences. In the U.S. alone, direct losses attributed to the severe winter of 1976 were estimated by the Department of Commerce at over $\$ 36$ billion.

While attempts to organize a U.S. national climate program began under President Nixon, it was President Carter who fully recognized the importance of both climatic variation and climate change, particularly as factors to be considered in setting national energy policy. The climate issue was not a priority for his successor, although President Reagan did promote international environmental actions on protection of the ozone layer through the Vienna Convention on the Protection of the Ozone Layer in 1985 and the Montreal Protocol in 1987. Negotiations of a climate convention began in 1991 during President Bush's tenure.

The United States hosted the first negotiating session and called for developing a framework climate agreement much like the Vienna Convention for the Protection of Ozone Layer. European nations wanted a more specific and binding agreement, 
much like the Montreal Protocol, with specific targets and timetables for reducing $\mathrm{CO}_{2}$ emissions.

Largely based on projected economic impacts, the U.S. rejected any form of targets and timetables. Instead U.S. policy focused on three main principles: actions taken by governments should be based on a 'no regrets' policy, namely involving policies and programs that are useful in their own right; actions should reflect a 'comprehensive approach', namely including all greenhouse gases and all sources and sinks; and actions should be voluntary with non-binding targets and timetables.

These policy objectives were a direct manifestation of the Bush Administrations's approach to environmental policies and their assessment of climate change. The concept of 'No Regrets' was a reflection of the scientific uncertainty surrounding climate change. The 'Comprehensive Approach' reflected the idea of using market approaches to setting environmental policies. Support for non-binding targets was a manifestation of Republican views on non-government interference in setting environmental regulations.

In the final agreement E.C. countries reluctantly accepted these elements. However, they unilaterally declared specific and in some cases aggressive targets and timetable. Several nations began to develop national programs to achieve such targets. Some E.C. and other OECD countries have, however, been unable to meet their original target goals. Japan, for example, is projecting a $3.1 \%$ increase in $\mathrm{CO}_{2}$ emissions over 1990 levels in the year 2000. Canada is currently projecting to overshoot their target by the year 2000 . A complete picture of whether all developed countries will meet their goals will not be possible until all these countries complete their national plans.

While scientific evidence may have been the underlying factor in motivating international action, the negotiating process quickly expanded to include debate on major issues of economic and social policy. The negotiations became part of a larger international debate on technology transfer, north-south economic difference, international financing and economic growth. The final text of the climate convention is the first international agreement to reflect elements of sustainable development.

At the UNCED conference in Rio de Janeiro, President Bush was one of 154 heads of state to sign the United Nations Framework Convention on Climate Change (FCCC). He committed the U.S. to early ratification of the Convention and to the development of a national plan by January 1993. In October 1992 the U.S. Senate ratified the Convention, becoming the fourth country to do so.

Subsequently, President Clinton in his Earth Day speech of 1993 committed the U.S. to a national goal of stabilizing greenhouse gas emissions at 1990 levels in the year 2000 and continuing the trend of reducing emissions thereafter. The U.S. released the Climate Change Action Plan in October 1993 and committed to revising the plan every two years. 
The present level of commitments of governments to the Climate Convention and possible future amendments or protocols reflect four major policy issues:

1. Scientific evidence for climate change: International scientific cooperation and assessments were essential in building and developing a scientific and policy consensus that global warming was a significant environmental risk, although the social and economic impacts remain uncertain. Future changes to the Convention will be affected by ongoing scientific assessments and technological discoveries.

2. Economic impact: U.S. policy makers were greatly influenced by macroeconomic studies of the possible costs of policy actions taken to mitigate climate change. Any future policy actions will still be subject to extensive cost analysis. However, current thinking in Washington and elsewhere is that through the transfer of more efficient energy and other environmental technologies, greenhouse gas emissions can be reduced and economic growth stimulated at the same time. As more environmental and technical solutions are demonstrated, the issue of climate change may become less formidable.

3. Implementation of environmental policy: The climate change issue is not divorced from broader environmental policy issues. Five U.S. Presidents have contributed to the formulation of U.S. environmental policy: Nixon, Carter, Reagan, Bush and Clinton. During their tenure U.S. thinking about environmental policy has evolved and changed many times. For a large part of this period (12 years) the predominate mood among policy officials in Washington favored less government regulation and more reliance on free market system. The use of government programs designed in Washington, to limit greenhouse emissions was not in favor. In contrast the current Administration favors forming partnerships with industry to overcome market failures and barriers that prevent the penetration of new technologies.

4. North-South issues: At the center of much of the climate debate were two issues. First, developing countries perceived the problem as one which was caused by overconsumption of resources in industrialized nations. Projections of their own rapidly growing emissions never entered the debate. Second, most developing countries had higher priority environmental problems, e.g., poor sewage treatment and air quality. The synergism between reducing greenhouse gas emissions and improving local air quality and energy efficiency was also never seriously discussed. Developing countries (and later countries in economic transition) focused on how to address the issue without impeding their own economic growth. They required some financial assistance and the transfer of technology on favorable terms. Discussions in other fora, on international financing for environmental issues led to the creation of the Global Environmental Facility (GEF) which became the central funding mechanism. for the climate Convention. U.S. policy makers were never very enthusiastic about creating special funds for international environmental issues. Recently, 
they have, however, worked hard to make the GEF an effective and transparent international organization.

This paper describes how the above issues interacted with one another over a period of two decades. During this period science, environmental, technology and economic policy have slowly merged. This public policy continuum is likely to embrace an even broader array of population and other human development issues in the next century.

\section{Part 1: The Early Scientific Years: 1970 to 1980 . Climate Modeling and Stratospheric Ozone Depletion}

At the beginning of 1970, the United States had four major numerical climate modeling centers. The nation's premier laboratory was the National Oceanographic and Atmospheric Administration's (NOAA) Geophysical Research Dynamics Laboratory (GFDL) located at Princeton University. For the next 20 years this laboratory pioneered research in climate modeling. Other research centers, largely supported by the National Science Foundation (NSF) were at the National Center for Atmospheric Research (NCAR) in Boulder, Colorado, UCLA in Los Angeles and at the Rand Corporation also in Los Angeles. Some time later another modeling laboratory was established by NASA at their Goddard Space Center in New York.

During the 1970s a combination of budget and policy decisions, along with the occurrence around the world of many anomalous weather patterns, set off a chain of events that led to the development of a national climate program.

NSF contributed to these events when, in 1970, it decided to eliminate its support for the Rand climate modeling program. The creative, but financially strapped Rand scientists turned to other federal agencies for financial support.

At roughly the same time, the Advanced Research Projects Agency (ARPA) blessed with the first large parallel processing computer - the ILLIAC IV was looking for additional research 'customers'. ILLIAC's financial demands had become so great that they could no longer be supported solely as a basic research venture. To the Rand team, climate research seemed a good candidate for funding because of the need to understand the national security implications of deliberate or inadvertent climate modification activities by the former Soviet Union. This concept seemed plausible at the time especially in light of a massive Soviet river-diversion project in the Arctic and because of speculative proposals being discussed for damming the Bering Straits. ARPA bought the climate project, classified it secret, and gave it the code name 'Nile Blue'.

The Rand climate modeling program was supported for a number of years. Despite its handicap of being based on simplified atmospheric equations and representing the atmosphere by only two interactive layers, Rand pioneered research in experiments with modified sea-surface temperatures, experiments with increased atmospheric dust (almost two decades before Nuclear Winter), and experiments 
using rigorous statistical analysis with control runs in general circulation model (GCM) experiments.

Successful though they were, all ARPA programs had to have an end. ARPA's model of operation was a pioneering 5 to 6 year program that either ended or was transferred to another agency for further development.

In the case of the ARPA climate program, two events propelled it to a home back at NSF. First, a Rand alumnus, Joe Fletcher, moved to NSF and brought with him a burning interest in climate change and an urge to establish a climate program within the federal government. About the same time, a conference at Brown University on paleoclimate research (also part of the overall ARPA Program) concluded that the present interglacial climate was about to end.

Several participants at the Brown conference wrote President Nixon suggesting that the federal government examine the premise that the world might return to glacial conditions. Joe Fletcher seized the opportunity of the conference and the subsequent letter to the President to propose a comprehensive climate research program. His ideas contributed to the ultimate development of the National Climate Program (NCP) in 1987.

In the meantime, the ARPA program was transferred to NSF in 1975 where it was renamed the Climate Dynamics Research Program. The Rand program was back where it started from.

As the new NSF program began, public attention on 'climatic' variations, such as extremes from one season to another, and the impact of those variations on society, was growing. In the $1970 \mathrm{~s}$, the occurrence of a number of anomalous weather patterns such as exceptionally cold winters in the U.S. and Europe in 1976, fueled debate on the causes and policy implications of climate variability and change. The long term trend of climate change was unclear and many felt that global cooling was the way of the future. The Nixon Administration took the first steps toward organizing a national climate program by creating in 1974 an interagency coordinating group.

Two years later Stephen Schneider, in his book The Genesis Strategy, ${ }^{1}$ laid the foundation for policy debates on climate change and on economic and social policies.

"The Genesis Strategy of maintaining large margins of safety to secure our means of survival can be applied to many of the urgent questions of human survival. One of these questions is climatic change, a phenomenon that deserves wide attention for several reasons: (1) It is often global in scope and concretely demonstrates potentially high risks to world stability; such risks can result from shortsighted political practices that stress short-term national solutions to problems that are often both long-term and world-wide; (2) Issues of climatic change have been underplayed or incompletely treated in most debates about the world's survival."

Parallel to the evolving debate on climate change during the 1970 s and early 1980 s, U.S. scientific and policy attention was also focused on the possible impact 
of chlorofluorocarbons (CFC) on the stratospheric ozone layer. A landmark paper published in 1974 by Mario Molina and Sherwood Rowland hypothesized that ozone, which is a gaseous layer in the stratosphere, was being depleted by CFCs and nitric oxides released from man-made products. ${ }^{2}$

Congress held hearings on the CFC issue in 1975. Ten years later the international community would sign the Vienna Convention for the Protection of Stratospheric Ozone which created a general obligation for nations to take "appropriate actions to protect the ozone layer" and created a mechanism for international cooperation in research and monitoring. The Convention also had a supplementary resolution, introduced by the U.S. directing the United Nation's Environmental Program (UNEP) to start international negotiations of a legally binding protocol. This became the springboard for the 1987 Montreal Protocol which established a specific timetale for phase out of the production and use of CFC chemicals.

A review of the history of the Vienna Convention and the subsequent Montreal Protocol (1989) from the time of the U.S. Congressional Hearings in 1975 shows many parallels to the history of events leading to the climate convention. ${ }^{3}$ With respect to both the issues of CFC and climate change, there were serious questions of scientific uncertainty, conflicting industry and government views, interagency disagreement and international negotiations all of which were resolved (in 10 years for the $\mathrm{CFC}$ issue) in an international agreement.

In the late $1970 \mathrm{~s}$, one of the main consequences of the CFC debate was to convey to the general public the concept of a real global environmental threat and the need for domestic and international action to address it. This issue helped to build a non-governmental environmental constituency in the U.S. which became very well organized in the subsequent climate negotiations, and to enhance the reputation of UNEP, which coordinated the negotiations of the Vienna Convention. ${ }^{4}$ This issue also served to forge an important alliance between the EPA and the Department of State that was crucial in resolving many domestic political issues and in implementing U.S. foreign policy. This same alliance proved effective in establishing the Intergovernmental Panel on Climate Change (IPCC) and in negotiating the climate Convention.

Public interest on environmental issues was also reinforced by the concurrent debate on whether supersonic transports (SSTs) had any effect on the atmosphere. ${ }^{5}$ These combined activities primed the public to be sensitive to concerns about global climate change and the seriousness with which the U.S. Congress would take such issues.

It is ironic that the propelling concern for climate research in the 1970 s was the possibility of climate cooling, rather than climate warming. Yet the theoretical basis for greenhouse induced global warming had existed for decades and was already a major policy concern in reports of the National Academy of Sciences (NAS).

The steady rise of $\mathrm{CO}_{2}$ in the atmosphere had been systematically measured by David Keeling since 1957 from a laboratory atop Mauna Loa, Hawaii. This 
observation record has continued to the present and provides one of the clearest and most well documented examples of man-made impact on the global environment. ${ }^{6}$ In 1957 the mean concentration of $\mathrm{CO}_{2}$ in the atmosphere measured at Mauna Loa was about 315 parts per million (ppm). By the end of the 1970 s the concentration rose to about $335 \mathrm{ppm}$.

The threat of man induced climate change emerged as a primary motivation for international research by the time of the World Climate Conference (WCC) in 1979. WCC Chairman, Robert White, worked hard at the conference to get international consensus on a declaration which would establish a World Climate Program. The Declaration concluded that "there is serious concern that the continued expansion of man's activities on each may cause significant extended regional and even global changes of climate. This possibility adds further urgency to the need for global cooperation to explore the possible future course of global climate and to take this new understanding into account in planning for the future development of human society."

The Second World Climate Conference, a decade later would call for a global agreement on climate change.

\section{Yearly Highlights}

\subsection{4}

[1] A United States Climate Program was organized by the Domestic Policy Council (DPC) to coordinate federal government research and to assess impacts of weather and climate change on society. ${ }^{7}$ The DPC concluded that "The [government] subcommittee finds that our present ability to anticipate and explain either natural fluctuations or man-induced changes of climate falls short of being useful to the planners and policy makers who must face these problems and short of what science and technology can make possible."

\subsection{5}

[2] U.S. Congress held hearings on stratospheric ozone depletion. ${ }^{8}$

[3] GFDL scientists Manabe and Wetherald perform the earliest computer simulations of greenhouse gas induced climate change by a general circulation model (GCM). The extensive GCM calculations were performed at a time when the fastest computer was about $10 \%$ the speed of a single processor of a present day computer. ${ }^{9}$

[4] The NAS published the first of many future reports on climate change, Understanding Climatic Change: A Program for Action ${ }^{10}$, which predominately addressed climate research needs.

[5] A NAS report in 1977, Energy and Climate, ${ }^{11}$ linked research needs to energy production and outlined the 'carbon dioxide problem'. A major question 
raised in the 1977 Energy and Climate Report reemerged as the ultimate objective of the 1992 Framework Climate Convention. "This report (Energy and Climate) has been addressed to what might be the climate impact over the next century or two of a major dependence on fossil fuels. In light of the rapidly expanding knowledge and interest in natural climate change, perhaps the question that should be addressed soon is, "What should the atmospheric carbon dioxide content be over the next century or two to achieve an optimum global climate?' Sooner or later we are likely to be confronted by that issue."

[6] Canada published a report which stressed that climate and climatic variability must be taken into account in the planning of nearly all facets of human life. ${ }^{12}$

\subsection{6}

[7] The Australian Academy of Sciences published a report concerned with the impact of climatic fluctuations on Australian agricultural and energy sectors. The report noted the potential for man-induced climate change. ${ }^{13}$

\subsection{8}

[8] After more than two years of Congressional debate and largely due to the efforts of California Congressman George Brown. President Carter signed the National Climate Program Act. The Act created a National Climate Program Office (NCPO) and Policy Board with responsibilities to prepare a national plan and to oversee its implementation. The NCPO functioned from 1978 until 1992 when its functions were transferred to other Administrative units.

\subsection{9}

[9] WMO and UNEP organized the First World Climate Conference. The conference resulted in the establishment of a World Climate Program (WCP). The Program predominately addressed data observations and research needs. A small climate impacts program was initiated by UNEP. Eleven years later, at the more political Second World Climate Conference, many countries would call for specific targets and timetables to reduce carbon dioxide emissions.

\section{Part 2: Science and Policy Begin to Merge: 1980-1987}

Over this 7-year period, the issue of man-induced climate change became more and more a policy issue. In the United States there was intense debate on whether sufficient scientific evidence existed to justify policy actions to arrest climate change. A steady stream of reports and assessments were prepared by national and international expert groups. 
At the beginning of the decade, greenhouse warming was a policy consideration at least in the context of national debate on energy policy and synthetic fuels (synfuels). The Energy Security Act of 1980 called for examination of the environmental consequences of energy development. Congress was particularly concerned about the buildup of carbon dioxide gases in the atmosphere. The Congress asked the NAS and the Office of Science and Technology Policy (OSTP) to review the issue.

The NAS report, published in $1983,{ }^{14}$ reaffirmed the prediction of a long term climate warming associated with increasing atmospheric $\mathrm{CO}_{2}$. The report took a cautious policy approach. Its key authors in presenting its conclusions saw the scientific results as being a flashing yellow (warning) light for policy makers.

At the same time, the Environmental Protection Agency (EPA) published a report, Can we delay a greenhouse warming?, which offered a first look at "whether specific policies aimed at limiting the use of fossils fuels would prove effective in delaying temperature increases over the next 120 years." 15 The report was more a red flashing light, raising the specter of a world on a collision course between the need for energy derived from coal and a global warming of potentially catastrophic proportions.

While U.S. policy makers were uncertain about appropriate responses to climate change, UNEP officials had a clear sense of purpose. Building on their success with the Vienna Convention, UNEP in their long range planning document in 1985 , called for a convention on climate change. UNEP began to lead international scientific efforts to establish the foundation for negotiating an agreement on climate change and in cooperation with WMO, and the International Council of Scientific Unions (ICSU) convened a joint scientific conference on greenhouse gases at Villach, Austria.

The conference report, published in $1986,{ }^{16}$ moved the climate debate forward by identifying the importance of trace gases, other than $\mathrm{CO}_{2}$, in contributing to global warming. Drawing on a paper published by Ramanathan et al. in 1985, scientists acknowledged that, if current trends continued, the increasing concentrations of trace gases would alter the equivalent doubling time of a $\mathrm{CO}_{2}$ induced warming from the later part of the next decade to approximately $2030 .{ }^{17}$ This information moved the spotlight from $\mathrm{CO}_{2}$ to all trace gases and accelerated interest in the need for policy actions.

It may not be widely appreciated that UNEP's efforts to promote a convention on climate specifically triggered the development of the Intergovernmental Panel on Climate Change (IPCC). In response to the recommendations of the Villach report, UNEP Executive Director Moustafa Tolba sent a letter to Secretary of State George Schultz urging the U.S. to take appropriate policy actions.

The NCP Policy Board debated the content of a response to the Tolba letter. The majority of federal agencies present did not support negotiations of a climate convention. The mood of senior officials then in Washington was that the underlying scientific evidence for global warming was inconsistent, contradictory and 
incomplete and did not justify policy actions that likely would be expensive. The Department of Energy felt strongly that the Villach report was inadequate because it was not prepared by government officials.

EPA and the Department of State supported the idea of a convention and suggested that perhaps it was timely for governments to prepare an international scientific assessment, especially in light of conflicting scientific evidence. This debate within the Policy Board led to the U.S. proposal for 'an intergovernmental mechanism', to conduct a government-led, scientific assessment of the climate change issue. This 'mechanism', when later presented to WMO and UNEP governing bodies in the form of intergovernmental resolutions, became the Intergovernmental Panel on Climate Change (IPCC).

At a time when it was difficult to get interagency agreement on any action, there was convergence (for different reasons) around the concept of an international scientific assessment. Some U.S. agencies clearly saw this as a means to buy time' before engaging in serious policy decisions. Others saw it as a necessary step similar to the scientific ozone assessment, which was useful in building policy consensus and eventually the Montreal Protocol. In the end the IPCC scientific report actually triggered the beginning of the climate convention process. ${ }^{18}$

The year of 1986 was significant in terms of congressional interest. Influential congressional leaders asserted that the issue of greenhouse warming was no longer only a science issue; policy options had to be considered. ${ }^{19}$ Congress, in the likes of Senators Chafee, Stafford, Bentsen, Durenberger, Mitchell, Baucus, Leahy and Gore, began to pressure the White House to take action on climate change. These Senators signed a letter to Dr. Frank Press, President of NAS on June 2, 1986, requesting the NAS to review the scientific issues. These senators were 'deeply disturbed' by the implications of published reports on $\mathrm{CO}_{2}$ induced climate change.

Debate on national environment, energy, and transportation policies continued, but with no real progress until after the election of President Bush in 1988.

In the public eye, the issues of global warming were highly polarized. Many members of Congress took the issue seriously; the White House generally did not. Many scientists were greatly concerned; some were extremely cautious. Near the end of 1988, the issue was an easy campaign target for candidate Bush who began to talk about the 'White House effect' to combat the greenhouse effect.

$\mathrm{CO}_{2}$ levels in the atmosphere were at about $350 \mathrm{ppm}$ in 1988.

\section{Yearly Highlights}

\subsection{1}

[10] The Council on Environmental Quality (CEQ) published a major report on energy use and climate change. ${ }^{20}$ The report was published in the last days of the 
Carter administration. It recognized that "people have altered the face of the planet throughout history, but the power of today's technology and our growing capacity to foresee, however uncertainly, the possible consequences of our acts put us in a new moral position. The responsibility for the $\mathrm{CO}_{2}$ problems is ours - we should accept it and act in a way that recognizes our role as trustees of the earth for future generations."

[11] CEQ published jointly with the Department of State 'Global Future: Time to Act', a plan to implement President Carter's Global 2000 report. $^{21}$ While the Global 2000 report and this action plan were rejected by the incoming Reagan Administration, many of the recommendations were later embraced by President Bush and the international community. This report introduced the concept of sustainable development, which was later fully articulated and given international focus in the report Our Common Future. "The key concept here is sustainable development. Economic development, if it is to be successful over the long term, must proceed in a way that protects the natural resource base of developing countries." The report called for a national energy strategy and more emphasis on energy conservation and renewable energy sources.

\subsection{4}

[12] Spending for the national program on carbon dioxide and climate exceeded $\$ 20$ million per year among six federal agencies. From 1978, the federal government spent more than $\$ 100$ million. This amount jumped to over $\$ 1.5$ billion annually by 1994.

\subsection{6}

[15] Congress requested the EPA to undertake two studies on impacts of climatic change and possible options in response to greenhouse warming, and to report by March 1988. The first study published in 1988 examined the effects of climate change on the U.S. The second report examined policy options to stabilize and reduce emissions of greenhouse gases. The policy report generated intense interagency debate because it identified the need for a broad spectrum of regulatory, fiscal and education measures such as increased automobile efficiency, accelerated use of renewable energy, strengthened appliance standards and carbon taxes. It was finally published in $1990 .{ }^{22}$

[16] The Department of Energy (DOE) prepared four 'State of the Art Reports' on what is known and what remains uncertain about greenhouse effect and changing climate. DOE made no policy recommendations, generally arguing that there was an inadequate scientific basis for policy actions on global warming. 
[17] By Executive order (March 6, 1987) the Committee on Earth Sciences (CES) was established to address overlapping issues related to scientific planning and coordination among federal agencies in the area of global and climate change. The CES became the major U.S. interagency scientific advisory group replacing the Policy Board of the NCPO. This action signified the first attempt by the executive branch to assume more directly control of the climate change issue.

[18] The President of the United States signs The Climate Protection Act (PL $100-204 ; 1987)$ which directed EPA and the Department of State to develop policy options for dealing with greenhouse climate change and for coordinating international activities and for EPA to prepare a report on the status of international scientific understanding of climate change. ${ }^{23}$

[19] Internationally, in the report Our Common Future, the United Nations World Commission on Environment and Development called for international action leading to sustainable environment. UNEP, continuing their pressure for action on climate change, commissioned the Beijer Institute in Sweden to organize conferences in Villach, Austria and Bellagio, Italy on developing policy options for managing climate change. ${ }^{24}$

[20] A Protocol on reducing CFC production and emissions was signed in Montreal, Canada. Several months later, a U.S. scientific expedition to the South Pole confirmed British research results that the stratospheric ozone layer over Antarctica was thinning. These new scientific findings confirmed the urgency for international action to reduce emissions of CFCs.

\section{Part 3: The International Community Meets the Challenge 1988-1992}

The four-year period between 1988 and 1992 was a time when environmental issues were often at the center of international politics. For the first time world leaders focused attention on such issues as climate change, ozone depletion and global deforestation. How to respond to the issue of global climate change became part of the 1988 presidential campaign. Candidate George Bush, in a September 1988 speech in Boston, declared "those who think we're powerless to do anything about the greenhouse effect are forgetting about the White House effect. As president, I intend to do something about it." President Bush, along with German Chancellor Helmut Kohl, did contribute to making environmental issues a significant portion of the communiques of the 1989 and 1990 Economic Summit of the industrialized nations (the so-called G-7.)

This same four-year period was marked by the warmest surface land temperatures of the last 100 years. In 1988, the Upper Midwest of the United States experienced the worst drought in 50 years. NASA scientist and climate modeler, James Hansen testified to the Senate Energy Committee in 1988 that he was 99\% 
certain that the unusually warm, globally averaged temperatures for the $1980 \mathrm{~s}$ could not have occurred by chance, but rather were the result of the buildup of greenhouse gases. ${ }^{25} \mathrm{He}$ went on to postulate that increasing the global temperature would increase the likelihood of extreme heat waves such as those occurring in 1988. This testimony heightened the public debate on greenhouse warming. A year later, in 1989, TIME, Newsweek, dozens of business magazines and even Sports Illustrated featured major cover stories about global warming.

The scientific community wrestled with difficult questions of confirming whether in fact there was empirical evidence of global warming, and whether all the possible interacting biological, atmospheric and oceanic feedback processes governing climate were in fact understood well enough to be portrayed in climate models. There were legitimate scientific uncertainties, many of which are still unresolved today. Yet, during this period a consensus was developing among the majority of international scientists that the risk of climate change was of sufficient concern that policy actions were necessary. Of course, many scientists disagreed.

Within this debate a few scientists established themselves as critics of global warming policy actions. They maintained that understanding of greenhouse warming and climate change was still insufficient to make informed policy decisions. One such group, working under the auspices of the Marshall Institute in Washington, issued a report (widely read in the White House) which proposed that "no policy response to climate change is justified because existing computer models are inaccurate and that answers to the problem will be forthcoming in three to five years if we pump money into improving computer modeling." 26 The report was strongly criticized by academic and government scientists for its lack of peer review and unrealistic optimism that resolution to complicated scientific problems would emerge in five years. ${ }^{27}$

A small but influential group of U.S.S.R. scientists led by the distinguished scientist, Mikhail Budyko, had a different approach to the problem of climate change. Budyko argued that greenhouse warming would actually be beneficial to society. Using diverse proxy data (e.g. biological or geomorphic indicators), this group attempted to reconstruct the climates of several past climatically warm geologic intervals which they viewed as possible analogues of future warm, greenhouseinduced climate periods.

Budyko concluded that during such past geologic times the geographic extent and diversity of flora and fauna expanded significantly and agricultural production in Russia increased. A future climate with these characteristics would significantly enhance the Russian and global economy. Budyko strongly believed in his methodology and predictions and at several international meetings went so far as to conclude that government efforts to reduce greenhouse gas emissions "would be a crime against humanity." 28

It is against this background of rising public interest and conflicting scientific results that the IPCC was launched in 1989. The creation of the IPCC involved a number of practical and political decisions such as how the IPCC would be orga- 
nized and which countries would have leadership roles. The first crucial question was who would chair the IPCC. Consensus quickly converged on the Swedish scientist Bert Bolin who was widely recognized for his scientific work and policy objectivity. He was elected chairman at the first IPCC meeting with representatives of Saudi Arabia and Nigeria given roles as vice chairs.

The IPCC as a whole established three working groups: Working Group 1 would review the state and knowledge of the science of climate and climate change; Working Group 2 would evaluate the expected social and economic impacts of climate change; Working Group 3 would evaluate possible policy responses by governments to delay or mitigate the impact of adverse climate change. As expected, the work of this last group proved the most contentious. In addition, a smaller, fourth working group was organized to address the specific problems and needs of developing countries.

U.S. scientific agencies (NOAA, NASA) wanted the U.S. to chair the science group; other agencies (State and EPA) wanted the U.S. to chair the policy working group. Hours of domestic and international debate ensued. In the end, the U.S. was elected chairman of the policy (response strategies) working group along with Canada, China, Malta, Netherlands and Zimbabwe as cochairs. Other countries like Japan would lead on specific subsections such as energy and industry. The chairmanship of the IPCC working group on science went to the U.K. with Senegal and Brazil elected as cochairs. The chairmanship of the Impact Assessment Group given was given to the U.S.S.R. with Australia and Japan as vice chairs. ${ }^{29}$

The first phase of work of the IPCC ended in $1990 .{ }^{30}$ In separate and sometimes stormy meetings the three working groups of the IPCC met and approved their final reports.

The IPCC's major achievement was the Scientific Assessment of Climate Change. ${ }^{31}$ Drawing on the work of hundreds of scientists around the world, and expertly led by the U.K., the report critically reviewed the body of empirical evidence for global warming and reviewed the theoretical and empirical bases for climate modeling. During the course of the review, several new climate simulations were undertaken.

The final results reaffirmed the theoretical basis for global warming, and validated the use GCMs as a means of simulating climate change. ${ }^{32}$ "The latest GCMs while by no means perfect are thus sufficiently close to reality to inspire some confidence in their ability to predict the broad features of the doubled $\mathrm{CO}_{2}$ climate at equilibrium."

While the report was careful to underscore the uncertainties in both empirical and theoretical knowledge, it concluded that "the potential serious consequences of climate change on the global environment give sufficient reasons to begin adopting response strategies that can be justified immediately even in the face of significant uncertainties."

The IPCC scientific assessment broke new ground by attempting to account for the impact of a greenhouse gas on the radiative balance of the atmosphere by using 
an index that accounted for both the greenhouse effect of the gas and its lifetime in the atmosphere. This index is called the Global Warming Potential (GWP). ${ }^{33}$

The report also stressed that although it was an indication of scientific understanding in 1990, the "basic conclusions concerning the reality of the enhanced greenhouse effect and its potential to alter global climate are unlikely to change significantly."

Of the three full reports, the IPCC scientific assessment was a first rate job reflecting considerable international scientific debate and critical review. Only the U.S.S.R. felt excluded from the Working Group 1 process and uncomfortable with the overall results. ${ }^{34}$

The other two reports on policy and impacts are uneven in overall quality. Given the uncertainties about regional climate change, the limited number of global impact studies, and the lack of time to conduct new analyses, the report of the impacts working group became largely a compendium of ongoing impacts research and was presented without much critical review. The response strategies (policy) report (Working Group 3) was the most difficult to organize and write, since all participants knew it would have a significant impact on the upcoming negotiations of a climate convention. It was evident early in the IPCC process that it was too early to achieve consensus on policy issues which were so sensitive to many countries and to agencies within governments.

Working Group 3 became a forum for debating issues which would later be negotiated in the climate convention. For example at the IPCC WG-3 meeting in Washington in 1990, White House Counsellor C. Boyden Gray and Assistant Attorney General Richard Stewart gave a 'Saturday Seminar' on the concept of a 'comprehensive approach' for dealing with greenhouse gases. ${ }^{35}$ The comprehensive approach by definition allowed the sources and sinks of all greenhouse gases to be included in any accounting system for greenhouse gas reductions. As it turns out, certain CFCs which are ozone depleting substances are also greenhouse gases. As such they are included in the comprehensive approach, despite the fact that governments had already committed in the Montreal Protocol to reduce their emissions. The E.C. was not happy with this concept, which became a key element of the U.S. position during negotiations of a framework agreement. In the end the U.S. dropped CFCs from the comprehensive approach.

The entire collection of IPCC working group reports were published without full government endorsement. The IPCC itself chose only to debate and approve a final 'Policy Maker's Summary' for each working group. At the final IPCC meeting in Sweden, key recommendations of the summary report, were intensely debated, and on the last night, the meeting came close to failure. Individual countries and groups of countries began to position themselves for the upcoming negotiations. Certain words began to take on enormous importance. For example, in an effort to protect their interests, OPEC countries for the first time argued strongly for the wording 'safe' anytime it was used in reference to nuclear power or energy efficiency. Russia, especially unhappy about the conclusions of the scientific report, 
argued for inclusion of Budyko's paleoclimate scenarios. India, speaking for the G-77, insisted on language that put the problem of climate change squarely on the backs of industrial countries. The final hours of the IPCC were not a pretty picture.

Intense lobbying by both government and non-government organizations with politically important countries (U.S.S.R., India, Brazil) finally yielded compromises by dawn of the day of departure for most delegations. It was clear to all from the intensity of the final debate that negotiations of a framework agreement on climate would not be easy.

The results of the IPCC were presented at the Second World Climate Conference (WCC) which convened in Geneva in October. Occurring 11 years after the first WCC, this meeting produced a technical summary and a Ministerial Declaration calling for negotiations on a climate convention to begin as soon as possible. At the meeting, the U.S. and E.C. countries aired their different views on the goal of stabilizing greenhouse gases. Several heads of state attended the meeting including President Hussein of Jordan (who predicted the deliberate Iraqi destruction of Kuwait's oil fields). ${ }^{36}$

In December, 1990, the United Nations General Assembly (UNGA) accepted the IPCC final report and established the Intergovernmental Negotiating Committee (INC) as the designated entity to lead development of a framework convention on climate. The U.N. resolution called for the convention to be completed in time for signature 18 months later at UNCED conference in Rio de Janeiro in June 1992.37

The INC began its work in February, 1991, in Washington D.C. On that day, temperatures at Washington's National Airport broke a 108-year-old record, reaching a maximum of $70{ }^{\circ} \mathrm{F}\left(21{ }^{\circ} \mathrm{C}\right)$. The U.S. as host for the meeting wanted to demonstrate leadership and had worked intensely to develop America's Climate Change Strategy, a program plan that would "result in U.S. greenhouse gas emissions in the year 2000 equal to or below 1987 levels." The U.S., for the first time, called for a climate convention in time for signing at the UNCED Conference. ${ }^{38}$

The first negotiating session moved slowly. Seventy-six speakers made presentations in the first three days of the meeting. Many developed countries had hoped that the first INC would produce a draft climate agreement, drawing extensively from the final report of the IPCC response strategy working group. It was soon realized that this aspiration was unrealistic considering that much of the INC's time was dissipated on procedure issues and elections of a chairman and vice-chairman.

At the end of the first INC meeting, Jean Ripert of France was elected chairman and a host of other country representatives were selected for geographic balance as vice-chairs. No decision could be reached, however, on the chairpersons of the two main working groups - one on 'commitments' and another on 'mechanisms', and action was deferred until the second INC meeting. ${ }^{39}$

The INC would move in slow steps. First it established two working groups (commitments and mechanisms) which began debating ideas and elements that 
could be included in an agreement. Each working group then prepared a text of elements of a framework agreement. In December 1991, the two texts were combined into one unified text.

A central issue in the INC debates was the concept of setting specific targets and timetables for reducing greenhouse gas emissions. This concept was first introduced in 1988 at a world conference, hosted by Canada, on the 'Changing Atmosphere: Implications for Global Security'. The final report of this conference called for a framework treaty (much like the Vienna Convention) for protection of the atmosphere (including issues of climate change, ozone depletion and atmospheric pollution). The Conference report, by calling for $20 \%$ reductions in carbon dioxide emissions by the year 2000 , marked the beginning of the debate on targets and timetables. ${ }^{40}$

Based on the uncertainty of predictions of key economic indices, such as world fuel prices, and uncertainty over the consequences of some proposed actions, such as a carbon tax, the U.S. was flatly opposed to any targets and timetables. There was also concern that Congress would mandate targets without sufficient information on the economic consequences. Why some E.C. countries supported targets and timetables knowing that these targets could not be met without some costs is complicated and subject to many different interpretations. At the time, most of the analyses in Europe were based on simple linear programming models that produced results showing substantial savings over the lifecycle of more energy efficient technologies. Few macroeconomic models had been run in Europe. Our assertion is that setting targets and timetables became for many European governments symbolic of showing political leadership by challenging the U.S. Remember that the negotiations began after a period of eight years during which the U.S. was largely perceived as a reluctant partner in international issues and had denied that climate change was an important problem. ${ }^{41}$ It also came at a time of great euphoria in Europe. Communist governments in many countries were losing power. The E.C. was moving quickly toward monetary and social union. This excitement carried over to envirommental policy as many European ministers vied to make Europe the center of influence on environmental issues. These ministers also saw targets and timetables as a means of motivating their own governments (especially trade and finance ministries) to move policies in a more green direction.

While rejecting the idea of targets and timetables, the U.S. did propose that it would commit to preparing a national plan, describing in detail its programs for reducing greenhouse emissions. The plan would be completed within one year of the signing of an agreement. In early 1991, when negotiations began, U.S. policy makers were uncertain about whether the U.S. could stabilize emissions. It wasn't until 1992 that EPA, DOE and CEA analysts converged on an agreed set of numbers that projected greenhouse emissions for the year 2000 as being close to 1990 levels. $^{42}$

During the negotiations, three senior U.S. officials were most influential in formulating U.S. policy. The group included President Bush's Chief of Staff John 
Sununu, Michael Boskin, Chairman of the Council of Economic Advisors (CEA) and Richard Darman, Director of Office of Management and Budget (OMB.) The group had three major concerns.

First, in government and academic circles there was considerable disagreement on estimates of the cost of various policy options. The range of possible economic effects is illustrated by two reports published in 1990. The Economic Report of the President, prepared by the CEA, asserted that the cost of switching to less polluting energy systems could cost " $\$ 800$ billion under optimistic scenarios of available fuel substitutes and increasing energy efficiency to $\$ 3.6$ trillion under pessimistic scenarios between now and 2100."

The Congressional Budget Office of the U.S. Congress later published an economic report which suggested that a phased approach to carbon taxes will have a 1 to $2 \%$ impact on total GNP. ${ }^{43}$

It was ironic that during the first INC meeting in February, 1991, a report published by the Congressional Office of Technology Assessment argued that the U.S. could reduce its $\mathrm{CO}_{2}$ emissions by 29 to $33 \%$ at minimum costs within the next 25 years. ${ }^{44}$ At the same time, internal memos from the CEA portrayed the expected costs as significant. The divergence of views on costs was a compelling reason for the U.S. to resist targets and timetables.

The senior policy officials were also concerned about the possible financial commitments the U.S. would have to assume under the yet to be drafted climate convention. Their concerns relate back to a similar issue dealt with under the Montreal Protocol.

As mentioned earlier, the Vienna Convention and the Montreal Protocol were often thought of as models for climate convention. One component of the Montreal Protocol as amended in 1990 was the creation of a special fund by governments to assist less developed countries develop substitutes to ozone-depleting CFCs. At first both Darman and Sununu opposed creating such a fund, fearing that it would establish a precedent for future international agreements. Negotiations of the amendments to the Montreal Protocol nearly collapsed on this issue. Direct appeals from the EPA Administrator, William K. Reilly, and key industry CEOs to President Bush reversed this decision and the U.S. agreed to contribute to the fund although with strong language that it was not a precedent for future activities. ${ }^{45}$

Finally, the senior policy officials were unconvinced that the scientific evidence for global warming justified the cost of mitigation.

These factors combined with their general mistrust of the intentions of the E.C. led President Bush's economic team to take a strong position against policy actions. ${ }^{46}$

As the negotiations preceded, public attention was largely focused on the concept of targets and timetables. In advance of the second INC meeting in June, Michael Haseltine, Britain's then Secretary of State for the Environment visited Washington. One of Haseltine's main purposes was to attempt to bridge the gap between the United States and the E.C. on the issue of targets and timetables. The 
U.K. had proposed, in advance of his visit, that the E.C. would accept the comprehensive approach (minus CFCs) if the U.S. accepted the need for a phased-in approach to targets for $\mathrm{CO}_{2}$ and other greenhouse gases (see reference 35). The U.S. rejected this proposal.

A week after Haseltine's visit to the U.S., the second session of the INC convened in Geneva in June. European countries were now beginning to support commitments to greenhouse gas reductions. Germany, for example, was strongly committed to a 25 to $30 \%$ reduction in $\mathrm{CO}_{2}$ emissions from 1987 levels by 2005 , a proposal largely viewed as possible only because of the potential 'emission windfall' likely to result from the unification of Germany. France was committed to stabilizing $\mathrm{CO}_{2}$ at 2.0 metric tons per capita by 2000 . The U.K. was commited to stabilizing $\mathrm{CO}_{2}$ at 1990 levels by 2005. Japan was prepared to stabilize per capita $\mathrm{CO}_{2}$ by 2000. Canada was committed to stabilizing all non-CFC gases at 1990 levels by 2000 .

The debate on targets and timetable continued until the two-week period before the final negotiating session. At that time it became abundantly clear to the E.C. and others that the U.S. position was immutable. Only then did all parties agree to a compromise.

As the INC continued their work, a wide range of economic and social issues began to be debated. Addressing climate change was becoming more and more an issue of financing and technology transfer.

Many developing countries maintained that industrialized nations had caused the problem of global warming and were therefore responsible for addressing it. The group of developing countries (so-called G-77) insisted on 'common but differentiated commitment', reflecting the wide capabilities of members of the G77. Some members of the G-77 felt they should have no obligations at all under the Convention, considering their need for economic growth. Instead they called for 'new and additional' financing to help reduce their emissions of greenhouse gases.

India made an important contribution to the negotiations by proposing that commitments and financial resources be balanced. In other words, if the developing world committed to reducing their future emissions, they should in turn receive appropriate financial support. This concept was in fact incorporated into the final agreement.

While many industrialized countries were willing to financially help less developed countries, few industrialized countries wanted to establish more than one central funding mechanism. In. 1989, at a meeting of the World Bank's Development Committee, France and Germany proposed a new international financial mechanism which later became the Global Environment Facility (GEF). The GEF was conceived as a special funding mechanism to address emerging global issues, including climate change.

During the course of the INC negotiations, developed countries proposed that the GEF become the centralized financial support system for implementing the 
convention. World Bank officials attended the fourth INC meeting in December 1991 where they briefed delegates on the concept of the GEF. The GEF received mixed reactions from developing countries, many of whom disagreed with the operating procedures of the World Bank. Elements of the environmental community also viewed the GEF with suspicion because of its non-participatory management structure and the environmental policy and impacts of large projects supported by the Bank. This concern subsequently led developing countries to argue for a separate 'Green Fund' other than the GEF.

Later, the GEF was established as an interim mechanism, in the convention with a clear recognition that it would be restructured and would receive its policy guidance from the participating governments. ${ }^{47}$

The need for technology and technology transfer was recognized by both developing and developed countries. Both the U.S. and U.K. issued reports on how various technologies could be used to reduce greenhouse gas emissions. Several developing countries wanted access to technology, often on a preferential and non-commerical basis.

During the course of debate on commitments, the E.C. introduced the concept of "stabilizing greenhouse gases at levels which prevented dangerous anthropogenic interference with climate and that would allow ecosystems to adapt naturally." This important concept whose origin can be traced back to 1977 (see [5]) was later included in the final text.

The fifth session of the INC took place in New York in February, 1992. Only four months remained before the UNCED conference and governments expressed concern that the climate agreement would not be ready for the upcoming world event. President Bush refused to commit to attend the Rio conference until a satisfactory climate agreement was achieved. The President's attendance at Rio was a key negotiating point for the United States.

While the U.S. remained determined to avoid a binding commitment for target and timetable, it made a major concession on financing at the February INC meeting. At the urging of senior officials of the Treasury, EPA and OMB, the President made a decision to change U.S. policy with regard to financial assistance to developing countries. The U.S. for the first time acknowledged the need to provide financial resources to developing countries to permit their full participation in the Convention. The U.S. announced a commitment of $\$ 50$ million to the core fund of the GEF and $\$ 25$ million during the next two years to be used for studies by developing countries to inventory their greenhouse gas emissions (so-called 'country studies'), to conduct impact assessments, and for evaluations of mitigation options. ${ }^{48}$ (By September, 1994, nearly 50 countries had received financial and technical assistance for country studies.)

In early April, approximately a week before the final negotiating session, the U.S. released a white paper titled U.S. Views on Climate Change. The paper, the product of new and difficult negotiations between EPA and DOE, reanalyzed likely emission reductions from current programs. The analysis demonstrated that the 
U.S. could reduce its emission by 125 to 200 million metric tons of carbon by the year 2000 - within 1.5 to $6.0 \%$ of stabilization. While environmentalists and other governments assumed that these results would allow the U.S. to accept the E.C.'s proposal for a target and timetable, senior White House officials remained unswayed in their opposition.

At the final INC meeting, the U.S. maintained its position against binding targets and timetables because it believed that factors such as population growth, world fuel prices and economic growth could seriously push U.S. emissions toward the high end of the projected range. There was a strong perception in the Bush administration that a binding commitment to stabilize could force the U.S. to adopt significant policy actions with unforeseen economic consequences. There was also a strong belief that the E.C. position was untenable. In the months following Rio, these views have proven to be partially correct, since the cornerstone of E.C. policy, i.e. the E.C. carbon tax, has yet to be agreed upon.

Once again the U.K. tried to resolve outstanding differences between U.S. and E.C., newly appointed British Environmental Minister Michael Howard arrived in Washington in April for final consultations. Recognizing that a convention without the U.S. as a signatory would be a significant loss, the U.K. made a concerted effort to reach final agreement with the United States before the final negotiating session.

At the State Department British negotiators drafted a text on emission goals for the year 2000 that captured, although in a convoluted way, both U.S. and E.C. interests albeit in a non-binding fashion. This key paragraph ${ }^{49}$ assured that a convention would be completed. U.S. negotiators were happy with the text and moved quickly to sell it to key administration officials who accepted the compromise language and presented it to President Bush. The President concurred and called key heads of state to urge them to accept the language. Canada, Australia, and France supported the compromise as the best that could be achieved in order to get the President to the Earth Summit in Rio. Many European countries reluctantly accepted the compromise. Within a few days, the text was presented to the INC as a Chairman's draft.

The INC chairman's gavel went down for the last time late in the afternoon on Saturday April 11, 1992. Two days later, Maurice Strong, Secretary General of the UNCED conference visited the President to invite him once again to attend the so-called Earth Summit. The President graciously accepted.

All the issues of finance, technology transfer and climate change converged at the Earth Summit in Rio de Janeiro in June 1992. More than a hundred world leaders met in Rio to sign the climate convention and to lay the foundation for international programs for sustainable development. By the end of 1992, the United Nations had established a new Commission on Sustainable Development and the INC began to plan for its implementation. 


\section{Yearly Highlights}

\subsection{8}

[21] The U.S. Congress introduced legislation (National Energy Policy Act S. 2667; Global Environmental Protection Act S. 2663) to establish a national energy policy and to reduce global warming due to greenhouse gases. The National Energy Policy Act was signed by President Bush in 1992.

[22] The UNGA adopted a resolution recognizing climate as 'a common concern of mankind'.

\subsection{9}

[23] In January the UNGA adopted Resolution 43/53 "protection of global climate for present and future generations of mankind." The resolution codifies the IPCC and calls upon the "IPCC to define elements for inclusion in a possible future international convention on climate."

[24] In February, Secretary of State James Baker addressed the first meeting of the IPCC Working Group on Response Strategies held in Washington. Baker said that "we can probably not afford to wait until all of the uncertainties have been resolved before we do act. Time will not make the problem go away." And "while scientists refine the state or our knowledge, we should focus immediately on prudent steps that are already justified on grounds other than climate change. These include reducing CFC emissions, greater energy efficiency and reforestation." This was Secretary Baker's only speech, because he then recused himself from further involvement on the basis of a potential conflict of interest.

[25] In Geneva, Switzerland, 163 representatives from 43 governments as well as 29 observers met for a discussion of possible means of implementing response options to deal with potential climate change. The workshop focused on a framework convention on climate change. President Bush issued a statement endorsing actions leading to a fall workshop where the full range of financial, economic, technical and legal issues related to global climate change would be discussed.

[26] Support for the work of the IPCC was endorsed by the G-7 Heads of State meeting in Paris in July (Summit of the Arch) where leaders promoted limits on emissions of greenhouse gases and forest protection.

[27] The first ministerial-level meeting on global warming was held at Noordwijk, Netherlands. Representatives of 68 countries made commitments to stabilize levels of carbon dioxide emissions by the year 2000. The U.S. with support from Japan and the U.S.S.R. blocked passage of a declaration that would have set specific goals.

[28] The Second Scientific Assessment of Stratospheric Ozone was published. ${ }^{50}$ Participating governments agreed in London to a faster phase out of CFC chemicals than called for in the Montreal Protocol. The so-called London amendments required all CFCs to be phased out by 1995 . 
[29] India hosted a meeting of developing countries to examine the implications of a climate convention for third-world nations. The conference produced one of the first statements by the developing countries that industrialized countries had caused the problem of global warming and were responsible for both taking actions to address it and providing financial support to developing countries. This issue became one of the most contentious in all of the negotiations.

[30] The NAS released a report suggesting that the U.S. could significantly reduce its emissions of $\mathrm{CO}_{2}$ with minimum economic impact. Many other reports were soon published giving a significant range to the expected costs of adapting greenhouse gas emissions. (See for example, the Economic Report of the President, January 1990). EPA developed several energy efficiency programs (e.g. Green Lights) and produced crucial analytical data that eventually moved the U.S. to accept the terms of the framework agreement. ${ }^{51}$

[31] In December President Bush met with Soviet Leader Mikhail Gorbachev in Malta. The U.S. offered to host the first conference to negotiate a framework convention on global climate change, after the IPCC working groups submitted their final report.

[32] The year ended with the UNGA approving resolution 44/228 authorizing the UNCED conference in Rio in June 1992.

\subsection{0}

[33] The GEF was created for a three-year pilot period. Staff of the World Bank, United Nations Development Program and UNEP submitted operational and policy guidelines for the implementation of GEF. By the end of 1992, the GEF emerged as the primary funding mechanism for dealing with global issues.

[34] Canada published their Green Plan, elements of a national program to address environmental problems. The plan described actions the federal government will take in support of the strategy to reduce greenhouse gas emissions, improve energy efficiency and foster use of alternate fuels.

[35] Second Meeting of the Parties of the Montreal Protocol met in London and amended the Montreal Protocol.

[36] In a follow-up to the meetings of the World Commission on Environmental and Development, environmental ministers from the Economic Commission Europe (E.C.E.) meeting in Bergen, Norway declared that the E.C.E. countries have "a major responsibility to limit or reduce greenhouse gases and other emissions and to lead a global effort to address this matter by promoting energy efficiency, energy conservation and the use of environmentally sound and renewable energy sources." The ECE ministers "pledged full support for the early completion of the work on a framework convention on climate change and the development of protocols dealing with, inter alia, greenhouse gases and forestation, with a view to signing not later than at the 1992 UNCED conference." 
[37] The UNGA established the INC with the mandate to negotiate a framework convention on climate with appropriate commitments by governments and to complete the negotiations in time for the UNCED Conference (UNGA Res 45/212.)

\subsection{1}

[38] U.S. National Energy Strategy was published. (First Edition, February 1991). Central to the plan was a reduction in greenhouse gas emissions through programs of energy efficiency and application of new environmental technologies. The plan included a great many 'green programs' developed by EPA and DOE.

[39] In the INC, Japan introduced the concept of 'Pledge and Review' which was supported by the U.K. and France. They proposed that following ratification of the framework convention, countries would state exactly what they would do to limit greenhouse gas emissions and that these pledges would be reviewed periodically by an intergovernmental team (perhaps even the parties to the Convention). Environmental groups were appalled by the proposal, calling it 'Hedge and Retreat'. Nevertheless the U.K. agreed to host a closed experts meeting on the proposal in August. ${ }^{52}$ While the Japanese proposal for 'Pledge and Review' was intensely debated, enthusiasm for the concept waned by the end of the meeting. G-77 declared the concept dead in its present form.

[40] At the third session of the INC in Nairobi in September, debate focused on the extent of commitments to reduce greenhouse gases. Norway proposed establishing a clearinghouse on emissions that could serve as a 'bank' for emission trading among countries. This concept was incorporated into the climate convention as 'joint implementation'.

[41] In advance of the fourth INC session the German Cabinet reaffirmed their plan for $25 \%$ reduction in $\mathrm{CO}_{2}$ by 2000 .

[42] Norway announced their intent to increase $\mathrm{CO}_{2}$ tax to the equivalent of $\$ 22$ per barrel. Australia eased their position slightly, referring to analytical work indicating that achieving stabilization (and even greater reductions) in Australia was feasible. In Brussels, on December 13 the E.C. announced a strategy to limit $\mathrm{CO}_{2}$ emissions and to improve energy efficiency. The 12 countries of the E.C. agreed to create a tax on carbon and energy use. Several hurdles would have to be overcome before such a tax could be implemented.

[43] In the middle of 1991, the U.S. NAS published Policy Implications of Greenhouse Warming. The controversial report received mixed reviews. The Academy's report found that a 10 to $40 \%$ reduction in greenhouse gas emissions could be achieved at low costs assuming a 1990 level of economic activity. At the same time, the report concluded that "people in the U.S. likely will have no more difficulty adapting to such a future change than to the most severe conditions in the past, such as the Dust Bowl." Several members of the Academy panel dissented from this view. The report did, however, emphasize the vulnerability of many nat- 
ural ecosystems. "Some natural systems of plants and animals would be stressed beyond sustainability in their current form."

\subsection{2}

[44] The Rio Conference began on June 4. Over 150 countries signed the FCCC.

[45] After a hearing by the Foreign Relations Committee and testimony by then Vice Presidential candidate Albert Gore, the U.S. became the first industrial country (third overall) to ratify the FCCC and to present its certificate of ratification to the United Nations in November of 1992.

[46] In December 1992, the INC held an initial meeting to begin the task of implementing the FCCC. The meeting dealt primarily with organizational issues, i.e., the establishment of two work groups to carry out the preparations. Prior to the meeting, significant political and economic events in Denmark, Czechoslovakia, Sweden, Germany and other European countries began to influence the steadfastness of European policy. The U.S. also had a new President elect. The diplomatic work had produced a global constitution for the atmosphere. The difficult task of making the convention work lay just ahead.

\section{Post Script}

Over two years have passed since the FCCC was signed by Heads of State and the diplomatic corps in Rio. Since then a new chapter in the history of international cooperation to protect the atmosphere has begun. The convention was ratified by the 50th country on March 21, 1994. It has entered into force and the first meeting of the Conference of the Parties will be held in Berlin in March 1995. Many important greenhouse gas-emitting countries, including the United States, Germany, United Kingdom, Mexico, India and China, were among the first to ratify. These countries and others now share a collective responsibility to both develop the institutional arrangements to implement the convention effectively and to adhere to national obligations under the convention. Many have already begun the task of preparing emission inventories and national communications plans.

Progress has also been made toward improving the capacity of developing nations and transition-economy countries to respond to climate change through increased technical and financial assistance. The U.S. initiative on Countries Studies is providing assistance to 50 countries for emission inventories, impact studies, and technical analyses. Several international institutions and countries are providing similar assistance. Also, negotiations to restructure the Global Environmental Facility to respond to the needs of the FCCC have been completed.

A new U.S. policy on global warming was announced by President Clinton on Earth Day (April 21, 1993). The President said:

"I announce our nation's commitment to reducing our emissions of greenhouse gases to their 1990 levels by the year 2000. I am instructing my administration 
to produce a cost effective plan ... that can continue the trend of reduced emissions."

This statement shifted the U.S. policy debate from a discussion of "whether to reduce emissions' to a discussion of 'how to reduce emissions'. It set aside concerns over the need to first improve the science. It explicitly recognized the need for action despite the lack of conclusive evidence of actual changes in the climate. Given this new policy, government departments and agencies directed their energy and talent toward analyzing over 200 options for achieving the President's objective. The failure of Congress to pass the BTU tax and the President's desire that the plan be cost effective i.e., have low societal costs and government expenditures, and be easily implemented, created a significant challenge.

The Climate Change Action Plan released by President Clinton and VicePresident Gore in October, 1993 met these challenges through 50 measures to limit emissions. The plan relies on a combination of voluntary and regulatory programs to increase energy efficiency, limit methane, encourage renewable energy sources, promote carbon storage in forests and limit the introduction of HFCs. It commited the U.S. to consider further measures to improve energy efficiency in automobiles by the end of 1994 and to review the effectiveness of the proposed programs every two years to determine whether additional actions are needed to meet the President's goal. The plan is grounded in the belief that economically efficient technical solutions are available and that obstacles to their adoption can be overcome through partnerships between government and industry. More recently, members of the environmental community have expressed doubts about whether the plan will meet the President's goal. They argue that changes in energy prices, higher than expected economic growth and shortfalls in appropriations to DOE and EPA will result in higher than expected emissions and that the Clinton Administration should implement additional mitigation measures.

Most other governments now recognize that stabilizing greenhouse gases at 1990 levels by the year 2000 will not be easy. Each country will have to search for the political leadership and for a combination of policies to encourage economic development, new technologies, energy independence and environmental protection. If they are to succeed, these policies will have to be promoted on the merits of their current economic, local environmental and other national benefits.

However, all the planned actions of industrialized nations will not stabilize greenhouse gas emissions beyond the year 2000. To achieve this goal, new technologies, more difficult policy decisions and amendments to the convention will be needed. In the 21 st century many rapidly developing countries will also need to be full partners in the battle to protect the world from global warming and other environmental threats. To do more with less, and do it more efficiently and economically, will become a global necessity not just environmental rhetoric. 


\section{Acknowledgements}

The authors appreciate the helpful discussions with John Perry, National Academy of Sciences and Gordon Binder, World Wildlife Fund. We are especially grateful to David Victor, Senior Scientists at IIASA, Laxenburg Austria, for his extensive and critical review. His comments significantly improved the quality of the paper. In addition to all the references cited in the text, we have drawn from unpublished speech materials provided by Daniel Reifsynder, Department of States. Naturally, we take full responsibilities for the opinions given in the text. Thanks also to Dunya Hecht, for patiently editing the manuscript.

\section{Appendix I: Acronyms}

ARPA Advanced Research Project Agency

CEA Council of Economic Advisors

CES Committee on Earth Sciences

CEQ Council for Environmental Quality

CFC Chlorofluorocarbons

DOE Department of Energy

DPC Domestic Policy Council

EC European Community

ECE Economic Commission of Europe

EPA Environmental Protection Agency

FCCC Framework Convention on Climate Change

GCM Global Circulation Model

GEF Global Environmental Fund

GFDL Geophysical Fluid Dynamics Laboratory

GWP Global Warming Potential

INC Intergovernmental Negotiating Committee

IPCC Intergovernmental Panel on Climate Change

NAS National Academy of Sciences

NASA National Aeronautics and Space Administration

NCAR National Center for Atmospheric Research

NCP National Climate Program

NCPO National Climate Program Office

NOAA National Oceanographic and Atmospheric Administration

NSF National Science Foundation

OECD Organization for Economic Cooperation and Development

$\mathrm{OMB}$ Office of Management and Budget 


\section{UNCED United Nations Conference on Environment and Development \\ UNEP United Nation's Environment Program \\ UNGA United Nation's General Assembly \\ WCC World Climate Conference \\ WMO World Meteorological Organization}

\section{References}

1. Schneider, S. H.: 1976, The Genesis Strategy, Plenum Pub., New York, 419 pp.

2. Molina, M. J. and Rowland, S.: 1974, 'Stratospheric Sink for CFCs: Chlorine Atom-Catalyzed Destruction of Ozone', Nature 249, 810-812.

3. Benedict, R. E.: 1991, Ozone Diplomacy, Harvard University Press, 300 pp. See also Hecht, A. D.: 1991, 'International Solutions to the Ozone and Climate Change Problems', Marine Technol. Soc. (MTS) J. 25, 3, 42-47.

4. For a discussion of the growth of the environmental community see, Shabecoff, P.: 1993, A Fierce Green Fire, The American Environmental Movement, Hill and Wang, 351 pp. Many old-line conservation groups such as the World Wildlife Fund were active for a long time in protecting wildlife. During the 1970's and 1980's environmental NGO's grew rapidly as Congress passed legislation on hazardous waste, clean air, and toxic substances. The active role of NGOs in global environmental issues grew in the 1980's as institutions such as the Natural Resources Defense Council and the World Resources Institute attempted to address the issues of both stratospheric ozone and climate change. Their strength and influence has grown, as was also seen in the U.S. debate on NAFTA.

5. Mormino, J., Sula, D., Patten, C.: 1975, 'Climatic Impact Assessment Program: Development and Accomplishments 1971-1975', Final Report DOT-TST-76-41, December 1975.

6. David Keeling has received many national and international awards for his foresight in establishing the Mauna Loa observing station and of course for his overall research. Considering the value of this program to today's understanding of climate change, it is ironic that during the 1980s some federal managers recommended terminating this program. Many others rallied to Keeling's defense and in the end the federal government did the right thing.

7. Domestic Council: 1974, A U.S. Climate Program, Washington DC.

8. Committee on Aeronautical and Space Sciences: 'Stratospheric Ozone Depletion. Hearings before the Subcommittee on the Upper Atmosphere', U.S. Senate, September 8, 9, 15, 17, 1975. U.S. Government Printing Office.

9. Manabe, S. and Wetherald, R. T.: 1975 , 'The Effects of Doubling the $\mathrm{CO}_{2}$ Concentration on the Climate of a General Circulation Model', J. Atmos. Sci. 32, 3-15.

10. United States Committee for the Global Atmospheric Research Program: 1975, Understanding Climatic Change, A Program For Action, National Academy of Sciences, Washington DC, 239 pp.

11. Geophysical Research Board: 1977, Energy and Climate, NAS, Washington DC, 158 pp.

12. Scientific Council of Canada: 1976, Living with Climatic Change, Proceedings of Toronto Workshop, Ottawa, 105 pp.

13. Australian Academy of Science: 1976, Report of a Committee on Climatic Change, Canberra, $92 \mathrm{pp}$.

14. NAS: 1983, Changing Climate, Report of the $\mathrm{CO}_{2}$ Assessment Committee, Washington DC, $493 \mathrm{pp}$.

15. U.S. Environmental Protection Agency: 1983, Can We Delay a Greenhouse Warming, Washington DC.

16. WMO: 1985, 'Report of the International Conference on the Assessment of the Role of Carbon Dioxide and other Greenhouse Gases in Climate Variations and Associated Impacts', Report of Meeting, Villach, Austria, 9-15 October 1985, WMO World Climate Program Report, No 661, $78 \mathrm{pp}$. 
17. Ramanathan, V., Cicerone, R. J., Singh, H. B., and Kiehl, J. T.: 1985, 'Trace Gas Trends and Their Potential Role in Climate Change', J. Geophys. Res. 90, 5547-5566.

18. The authors participated in this meeting and have a clear record of the discussion. We are asserting that an element of the U.S. support for the IPCC concept, at least by some agencies, was based on the view that the IPCC would slow down the push for a climate convention. The U.S. attitude toward a climate convention was reversed after the 1988 Presidential Election.

19. Committee on Environment and Public Works: 1986, 'Ozone Depletion, The Greenhouse Effect and Climate Change', Hearings before the Subcommittee on Environmental Pollution of the Committee on Environment and Public Works, United States State, June 10-11, 1986, United States Government Printing Office.

20. Council on Environmental Quality: 1981, Global Energy Futures and the Carbon Dioxide Problem, U.S. Government Printing Office.

21. CEQ and the Department of State: 1981, 'Global Future: Time to Act', Report to the President on Global Resources, Environmental and Population, U.S. Government Printing Office, Washington DC, 207 pp.

22. U.S. Environmental Protection Agency: 1988, The Potential Effects of Global Climate Change on the United States: Report to Congress, EPA, Washington DC, and Policy Options for Stabilizing Global Warming: Report to Congress, 1990, EPA, Washington DC.

23. The Climate Protection Act symbolically elevated EPA's role in leading the policy debate on climate change. EPA Administrator Lee Thomas would later try to use the authority of this Act to capture a policy lead, but this attempt is met with strong opposition from other agencies. Having won a major victory to protect the ozone layer, EPA would never capture full leadership on climate policy, instead it would serve as a catalyst for further actions. In cooperation with DOE, EPA would provide the essential analytical data necessary for developing consensus in the U.S. on policy actions.

24. WMO: 1988, Developing Policies for Responding to Climatic Change, World Climate Program Report No. 10, WMO, Geneva.

25. Hansen, J.: 1988, 'The Greenhouse Effect: Impacts on Current Global Temperature and Regional Heat Waves', Testimony before the Committee on Energy and Natural Resources, U.S. Senate, Washington DC, June 23, 1988. Hansen's testimony to Congress was given extra publicity when OMB attempted to modify the written text to make it conform to Administrative policy. The story was hyped by the press who charged that the Administration was censuring a government scientist. In fairness to all sides it should be noted that all testimony to Congress given by any official of any Administration is subject to OMB review. This does not preclude any scientist from expressing his own personal view.

26. George C. Marshall Institute: Global Warming, Recent Scientific Findings, Washington DC.

27. Schneider, S. H.: 1989, Global Warming: Are We Entering the Greenhouse Century?, Vintage Books (paperback edition), 342 pp. See in particular pages 328-330.

28. An analysis of the paleoclimatic approach used by Budyko is given in MacCracken, M., Hecht, A. D., Budyko, M., and Izrael, Y.: 1990, Prospects for Future Climates, A special U.S.-U.S.S.R. Report on Climate and Climate Change, Lewis Press, $270 \mathrm{pp}$.

29. The U.S. was a major contributor to the IPCC and several agencies wanted to lead U.S. participation in each of the groups. The balance of scientific coordination in the U.S. was now well in the hands of the White House through the CES (see item 17) and they took the interagency lead for the science review. The Department of State wanted lead of the IPCC policy working group and they assumed responsibility for coordinating U.S. participation. This left the impacts groups to be managed and the coordinating job was directed to one of the authors and EPA who had a long standing relationship with U.S.S.R. IPCC chairman Yuri Izrael.

30. The IPCC continues as an international advisory body and will prepare a second scientific assessment in 1995. In a report issued in September 1994, the IPCC scientific panel concluded that even if present levels of greenhouse gases were capped, atmospheric concentrations would increase for at least 200 years, reaching about $500 \mathrm{ppm}$ by the end of the century.

31. WMO, UNEP: 1988, Climate Change: The IPCC Scientific Assessment, Houghton, J., Jenkins, G. J., and Ephraums, J. J. (eds.), Cambridge University Press, London, 365 pp. 
32. Since the pioneering work by the U.S. in climate modeling, several other national centers have been established. The IPCC report reviewed climate model simulations carried out in the U.S. (at GFDL, NCAR and NASA) and in the U.K. (British Meteorological Office).

33. In the IPCC report, CFC gases were considered as strong absorbers of the surface IR. Their GWP as quoted in the report (1990) were large and positive ranging from about 300 to 6000 relative to $\mathrm{CO}_{2}$ as the reference gas. However, new analyses associated with the Ozone Scientific Assessment in 1991 suggested that the GWP for CFCs were smaller or even negative than previously estimated. As a consequence of this study, the emphasis on CFCs as a greenhouse gas was diminished.

34. Budkyo's hypothesis that paleoclimate analogues was a good approach to predicting the future was rejected by the IPCC scientific working group. This left the Russians somewhat unhappy with the 'completeness' of the IPCC report. While the methodology in this approach is still widely suspect, U.S.-Russian scientists are collaborating on more definitive ways to test the hypothesis.

35. Discussion paper: 'A Comprehensive Approach to Addressing Potential Global Climate Change' presented at an informal seminar 3 February 1990, U.S. Department of State. The intellectual background for this proposal is developed in Ackerman, B. A., and Stewart, R. B.: 1988, 'Reforming Environmental Law: The Democratic Case for Market Incentives', Columbia J. Environm. Law 13, 153-169.

36. Heads of state who spoke at the Second World Climate Conference included: H. E. Mr. Arnold Koller, President of the Swiss Confederation; His Majesty King Hussein of Jordan, Margaret Thatcher, Prime Minister of the U.K., H. E. Mr. Michel Rocard, Prime Minister of France, Hon. Edward Fenech-Adami, Prime Minister of Malta; and Hon. Bikenibeu Paeniu, Prime Minister of Tuvalu. Conference proceedings are published as Climate Change: Science, Impacts and Policy, Edited by Jill Jager and H. L. Ferguson. Cambridge University Press, 1991, 578 pp.

37. For a detailed discussion of the negotiating process and for a thoughtful and extensive analysis of provisions of the climate convention, the reader is referred to: Bodansky, D.: 1993, 'The UN Framework Convention on Climate Change: A Commentary', Yale J. Internat. Law, V. 18, \# 2, 451-558.

38. The Bush Administration, riding the wave of the campaign debate, began to promote an environmental posture. The Climate Action Plan drew on many voluntary programs which when fully implemented could significantly reduce greenhouse gas emissions. The support for a convention was meant to be only a framework convention. No one in the Administration was prepared to endorse binding protocols or emissions reduction targets.

39. Many NGOs were impatient with the progress at the first INC. The first session of the INC ended with the comment from David Doniger of the U.S. Natural Resources Defense Council that "global warming is now moving faster than these negotiations."

40. WMO, UNEP: 1988, Proceedings of the World Conference on the Changing Atmosphere: Implications for Global Security, Toronto, June 27-30, 1988. WMO/UNEP: WMO Doc 710 (1989). Canada hosted this conference and was very heavy handed in preparing the final report. The U.S. was never happy with the meeting and at first refused to attend. The U.S. did attend, but distanced itself from the final conclusions.

41. State Department participant in the negotiations, Dan Reifsnyder, offered the view that the concept of targets and timetables "captured and riveted the public's imagination. It provided a simple litmus test of a country's environment commitment. It required no painstaking feasibility analysis or tedious review of specific mitigation measures. It was political genius." Speech to 1992 Seoul Symposium on 'UNCED and Prospects for the Environmental Regime in the 21st Century', September 2, 1992, Seoul, Korea.

42. In April 1992, the U.S. released an analysis that said it could reduce emissions in the year 2000 (by voluntary actions) by $125-200$ million metric tons which would be about $7-11 \%$ below the projected levels.

43. Congressional Budget Office: 1991, Carbon Charges as a Response to Global Warming: The Effects of Taxing Fossils Fuels, Washington DC, 69 pp.

44. Office of Technology Assessment: Changing by Degree: Steps to Reduce Greenhouse Gases, Washington DC, 44 pp. 
45. The U.S. statement for the Second Meeting of the Conference of the Parties to the Montreal Convention, in London, June 6, 1990 said "any financial mechanism set out here does not prejudice any future arrangements the Parties may develop with respect to other environmental issues."

46. In advance of the G-7 Paris summit, William Reilly who was the Administrator of EPA during the Bush Administration briefed Bush's Cabinet on climate change. He reported that at the conclusion of the meeting Sununu told the Cabinet that the models on which climate change were premised were fundamentally flawed and the best atmospheric scientists had yet to become involved in climate research. At the same meeting Budget Director Darman called the concept of a climate convention, 'Clean Air for the Whole World'. Economic advisor Boskin told the President that an international treaty on climate change was a 'bet-you-economy' decision. (See Reilly, W. K.: 1994, Breakdown on the Road from Rio: Reform, Reaction and Distraction Compete in the Cause of the International Environment. 1993-1994, Arthur and Frank Payne, Lecture, Stanford University).

47. The terms of the GEF were renegotiated in 1994. The governance became more transparent and open to NGO involvement. Governments agreed to a replenishment of two billion dollars, with the U.S. agreeing to pay $\$ 430$ million. While in the past, under the Bush Administration, there was real reluctance to providing financial support for international funds, the Clinton Administration was more forthcoming.

48. The reader might find the U.S. position on international funding somewhat confusing. First the U.S. opposed funding for the Montreal Protocol fund, but later reversed direction. The U.S. at first also opposed funding for the GEF, but later committed to contribute funds in a bilateral fashion. The position was later changed to provide funds directly to the GEF and to contribute to a separate fund for developing country studies. Part of the changes reflected shifts in senior advisors to the President, part was due to the persistence of the EPA Administrator and other senior officials and part was due to a realistic evaluation of what it would take to conclude the climate convention in time for signing at Rio.

49. Article 4, Section 2: "Each of these Parties shall adopt national policies and take corresponding measures on the mitigation of climate change by limiting its anthropogenic emission of greenhouse gases and protecting and enhancing its greenhouse sinks and reservoirs. These policies and measures will demonstrate that developed countries are taking the lead in modifying longer term trends in anthropogenic emissions consistent with the objectives of the Convention, recognizing that the return by the end of the present decade to an earlier level of anthropogenic emissions of carbon dioxide and other greenhouse gases not controlled by the Montreal Protocol would contribute to such modification, and taking into account difference in these Parties starting points and approaches, economic structures and resource bases, the need to maintain strong and sustainable economic growth, available technologies and other individual circumstances, as well as the need for equitable and appropriate contributions by each of these parties to the global efforts regarding that objective."

50. WMO: 1989, Scientific Assessment of Stratospheric Ozone, WMO Global Ozone Research and Monitoring Project Report No. 20, Geneva.

51. EPA pioneered many programs to promote energy efficiency. One of the first was 'Green Lights', a program to convince businesses as well as state and local governments to adopt high-efficient and energy conserving lightning systems. Since its inception 'Green Lights' has attracted dozens of companies and state agencies which are beginning to show significant savings in energy costs. 'Green Lights' and many other energy efficiency programs were incorporated into the U.S. Climate Action Plan released in October, 1993.

52. Royal Institute of International Affairs: 'Pledge and Review Processes: Possible Components of a Climate Convention', Report of Workshop 1991, Royal Institute International Affairs, London.

(Received 23 May, 1994; in revised form 18 October, 1994) 